\title{
Wrong, but not failed? A study of unexpected events and project performance in 21 engineering projects
}

\author{
Wied, Morten; Oehmen, Josef; Welo, Torgeir; Pikas, Ergo
}

Published in:

International Journal of Managing Projects in Business

Link to article, DOI:

10.1108/IJMPB-08-2020-0270

Publication date:

2021

Document Version

Peer reviewed version

Link back to DTU Orbit

Citation (APA):

Wied, M., Oehmen, J., Welo, T., \& Pikas, E. (2021). Wrong, but not failed? A study of unexpected events and project performance in 21 engineering projects. International Journal of Managing Projects in Business, 14(6). https://doi.org/10.1108/IJMPB-08-2020-0270

\section{General rights}

Copyright and moral rights for the publications made accessible in the public portal are retained by the authors and/or other copyright owners and it is a condition of accessing publications that users recognise and abide by the legal requirements associated with these rights.

- Users may download and print one copy of any publication from the public portal for the purpose of private study or research.

- You may not further distribute the material or use it for any profit-making activity or commercial gain

- You may freely distribute the URL identifying the publication in the public portal 


\section{Wrong, but not failed? A study of unexpected events and project}

\section{performance in 21 engineering projects}

Morten Wied, Technical University of Denmark

Josef Oehmen, Technical University of Denmark

Torgeir Welo, Norwegian University of Science and Technology

Ergo Pikas, Tallinn University of Technology

Purpose: Most complex engineering projects encounter unexpected events through their life cycle.

These are traditionally attributed to inaccurate foresight and poor planning. Outlining a nonanticipatory alternative, resilient systems theory seeks to explain the ability to rebound from unexpected events, without foresight.

Design/methodology/approach: Investigating project resilience, this paper studies the relationship between unexpected events and project performance in 21 projects. We perform a systematic review of project ex-post evaluations 3-12 years after project completion.

Findings: First, we find that all projects encountered unexpected events, even when discounting planning error. Second, we find that, as a consequence, projects underperformed, not necessarily relative to formal criteria, but relative to competing alternatives - known or imagined - foregone by their implementation. Finally, we identify four types of resilient projects - superior, equivalent, compensatory, and convertible projects - as opportunities for building project resilience.

Originality: Departing from traditional efforts to 'de risk plans' and 'de-bias planners this paper focuses on the properties of projects themselves, as an alternative to improved foresight and up-front planning. 


\section{Introduction}

Most complex engineering projects encounter unexpected events through their life cycle, significantly affecting project performance (Miller and Lessard, 2001; de Bruijne and van Eeten, 2007; Cantarelli et al., 2010; McAdam, 2011; Flyvbjerg, 2014; Montanari and Querzoni, 2014; KPMG, 2017).

In traditional project management, this is widely held to be a problem of poor planning, optimism biases and deliberate deception (Morra and Thumm, 1997; Flyvbjerg, Bruzelius and Rothengatter, 2003; Samset and Volden, 2014; Merrow and Nandurdikar, 2018). Following Engwall (2003, p. 791), in this vein, research and practice has focused on solving two principal problems: 1) how to structure and plan project activities in order to meet the stipulated objectives, and 2) how to ensure that project activities are executed according to the stipulated plan. Efforts have focused primarily on 'de-risking' plans and 'de-biasing' planners, aiming at closing the gap between plan and reality (Cantarelli et al., 2010; Samset, 2010; Merrow, 2011; Samset and Volden, 2016).

While this has weeded out poorly conceived projects and unmasked deceptive planners, there is little evidence, that this has improved net performance over time, as projects have simultaneously become larger and more complex (Morris and Hough, 1991, p. 4; Miller and Lessard, 2001; Shenhar and Dvir, 2007; Rolstadås et al., 2011). In general, the performance of complex engineering projects has remained consistently poor over the past century, measured on monetary, environmental, and societal criteria (Flyvbjerg et al., 2003).

There is now a growing recognition that, in complex projects, unexpected events cannot be eliminated by up-front planning, regardless of its level of sophistication (de Meyer et al., 2002; Pich et al., 2002; Williams, 2005; Lenfle and Loch, 2010; Crosby, 2014; 2014; Kutsch et al., 2016). Fundamentally, it is not possible to undertake a complex project knowing the possible outcomes, their probabilities and their consequences. This places fundamental constraints on methods like robust decision making, realoptions evaluation and probabilistic risk management, premised on foreknowledge of some or all of these (Black and Scholes, 1973; Kaplan and Garrick, 1981; Lempert et al., 2003; Apostolakis, 2004; Kalra et al., 2014). 
Following Wied et al. (2020, p. 75), the unpredictability of complex projects challenges the presumption of 'information-before-action', underpinning traditional project management. Weick and Sutcliffe (2007, pp. 66-67) goes further, arguing that anticipatory planning may itself be part of the problem, in that it 1) reduces the number of things people notice, 2) constrains improvisation, and 3) presumes consistent outcomes if patterns of activity that worked in the past are repeated.

At the same time agility, adapted from software development (Beedle et al., 2001; Schwaber and Beedle, 2002), has proven difficult, as many complex engineering projects are not made up of independently functional parts, built by self-managing teams in time-boxed increments (Daneshgari and Wilson, 2006; Owen et al., 2006). Also in this vein, 'planned flexibility' has been limited to event-specific contingencies and switching between pre-defined classes of change (de Weck et al,. 2011, p. 187), while 'unplanned flexibility' has been shown to increase cost-overrun and further descope projects (Olsson, 2008, 2016).

\subsection{Project resilience}

Seeing an alternative to foresight and luck, there are now calls for a paradigm shift towards increasing resilience to unexpected events. Crosby (2014, p. 7) argued that, since the unknown cannot be planned in detail, an alternative method is to prepare with the expectation that unexpected events will occur, and that some solution will be needed. Crosby (2012, p. 2) defined 'project resilience' as the ability to recover from, or adjust easily to, misfortune or change. Prescribing a similar ethos, Miller and Lessard (2001, p. 204) argue for planning for the journey rather than planning the journey. Similarly, Nicholas

(2004, p. 325), argue that expecting the unexpected is often better preparation than preparing extensive plans and believing that uncertainty has been tamed.

In support of this view, Dvir and Lechler (2004) showed diminishing returns to planning; the effect of high-quality planning is almost completely overwritten by plan changes along the way, however, these changes themselves positively affect project performance. Reviewing turbulent historical projects Atlas, Polaris, Apollo, Manhatten, and Sidewinder - Lenfle and Loch (2010) and Lenfle (2014) found 
them not even remotely adhering to established planning practices, but attributed their success to the ability to manage unexpected events.

In project management, resilience remains an underdeveloped concept (Naderpajouh et al., 2020). Here, resilience research has been synonymous with transferring mindsets and attitudes of 'high reliability organizations' (HROs) (Roberts, 1984) to project organizations and teams (Turner et al., 2019; Karlsen and Berg, 2020). In this vein, Weick and Sutcliffe (2007) proposes organizational attitudes like preoccupation with failure, reluctance to simplify, sensitivity, commitment, and deference to expertise. Building on these concepts, Kutsch et al. (2016) prescribes 'mindfulness' in noticing, interpreting, preparing for, and containing unexpected events. Also inspired by HROs, Loch et al. (2006) - building on Pich et al. (2002) and Sommer and Loch (2004) - argue for 'learning' (replanning) and 'selectionism' (parallel trials), as the two fundamental strategies available to projects under deep uncertainty. Building further on this work, Geraldi (2010, p. 548) argues that "it is not a question of if, but when, unexpected events will emerge", and goes on to identify structural, social, and individual characteristics of project organizations successfully managing unexpected events. Crosby (2012) identifies 'launch conditions', for resilient projects emphasizing 'a lessons-learned culture', and 'clear reporting and decision structures', aiding projects overcome unexpected events.

Beyond organizational mindsets and attitudes, the properties of resilient projects themselves remain poorly understood (Aven, 2019; Naderpajouh et al., 2020). Following Aven (2019), by increasing the resilience of a project, its ability to manage unexpected events is, in principle, enhanced without the need to perform risk calculations; 'event-specific' contingency plans and risk registers are replaced by a form of 'general preparedness' (Aven, 2017, p. 536). Beyond this broad ethos, theoretical and practical understanding of project resilience remains underdeveloped.

Investigating two central research questions of project resilience, we ask: What is the relationship between unexpected events and project performance? And, what are shared the properties allowing some projects to succeed, despite, or even because of, unexpected events? Aiming to identify the properties of resilient projects, this paper investigates unexpected events and performance in 21 
engineering projects in Norway, evaluated 3-12 years after completion. In doing so, we seek to outline the theoretical underpinnings of project resilience and to identify criteria for planning and selecting projects for greater resilience.

The remainder of the paper is organized as follows: The next section outlines the research design of the paper. The third section reviews unexpected events and project performance in 21 engineering projects. The fourth section analyses criticisms and defenses of projects, in light of these events, and identifies properties of resilient projects. Finally, the fifth and sixth discusses our findings and concludes the paper.

\section{Research design}

The research design is a systematic review of 21 engineering projects in Norway. The study permits replication logic (Yin, 2014), so that projects are treated as a series of independent experiments used to confirm or disconfirm emerging conceptual insights. We follow Yin (2014, pp. 40-41) and Kvale's (1996, p. 233) principles of analytical generalization; that is, using data from one set of specific cases to develop theoretical concepts that apply to other cases.

\subsection{Data}

This paper is based on a dataset of systematic evaluations of 21 engineering projects in Norway, conducted 3-12 years after project completion. The evaluations are commissioned by the Concept Research Programme, NTNU, from independent external evaluators, as part of a quality assurance scheme of all projects requiring parliamentary approval. Under this scheme, project plans were subjected to independent review, resulting in rejection, revision, and/or recommendation of project plans, prior to parliamentary approval (Samset and Volden, 2014). The authors of this paper are unaffiliated with the Concept Research Programme, although we employ the dataset with permission.

By 2017,252 projects had been initiated under the scheme, and some 40 projects had been completed (Volden and Samset, 2017). About half of these -21 projects - were subsequently evaluated. With two exceptions, evaluated projects had been in operation for three or more years at the time of the 
evaluation. Each evaluation 1) compares project plans (after quality assurance) to the actuality of the project, and 2) scores each project on a set of standardized performance criteria (see below).

Evaluations were conducted using a standardized format (Samset, 2003), following a set of shared guidelines (The Concept Research Programme, 2015).

While about half of the projects completed under the scheme have been evaluated, these are not a random sample (Volden and Samset, 2017). Projects were selected for evaluation based on 1) the order in which they were completed, 2) to ensure spread across sectors (although defense projects are underrepresented because of classified information), 3) projects considered particularly instructive or informative, and 4) the likelihood of undertaking similar projects in the future.

Adopting this dataset, entails three important limitations of the study: 1) We see projects only through the eyes of evaluators (and interviewed stakeholders), 2) only as conveyed by the evaluation reports, and 3) only the project life cycle up to the time of the evaluation. With this in mind, the evaluations are not a reflection of 'daily life' of project implementation and does not record the 'lived experience' of project management or stakeholders. The evaluations focus primarily on major events and decisions of the project, doubtlessly omitting many small, but consequential events. Nor is there necessarily agreement on the evaluation results, and we are forced to accept the evaluators' view of the world. Being mindful of these limitations, for our purposes of studying the relationship between unexpected events and project performance, we consider the dataset a good record of 1) deviations from plan, and 2) assessments of project performance. Further, the dataset gives us insight into a wide range of projects over a comparatively long period of time.

Evaluated projects were implemented 2001-2012, and vary in size from NOK 300 million to NOK 5.6 billion. The dataset includes eight road projects, five building projects, four railway projects, two IT projects, and two defense projects. The projects are 'engineering' projects, involving the creative application of scientific principles to design or develop structures, machines, apparatus, or manufacturing processes (ECPD, 1947). All projects fall into Söderlund's (2004) category of interfirm projects, as these are single projects with multiple organizations involved in their implementation. 
Following, Shenhar and Dvir (1996), most projects project are 'low- to medium tech' (with the possible exception of the high-tech Project 21). Table I gives an overview of the 21 projects and the evaluation methodologies.

\section{Table I: Overview of projects and evaluation methodology about here}

Following a standardized format, each evaluation provides the background for initiating the project, an account of major events and decisions in the project before and after handover, their consequences for project performance, and (iv) performance scores on six performance criteria. Where needed, further clarification and verification on project detailed were obtained directly from the Concept Research Programme.

\subsection{Theory and methodology}

Etymologically resilience means to rebound, from its Latin root 'resilio' (Rose, 2017).

Operationalizing the concept of resilience, we turn to Holling (1973, p. 21), who first used the term to describe the ability to manage unexpected events, without the necessity of foresight. Grounded in General Systems Theory (Bogdanov, 1917; Bertalanffy, 1969), resilience can be defined as the ability to resist or recover from unexpected events, thus retaining or regaining an acceptable level of performance despite, or because of, unexpected events (Henry and Ramirez-Marquez, 2016; Aven, 2017). Building on Wied et al. (2020), the behavior of a resilient project can be illustrated as in Fig. 1 .

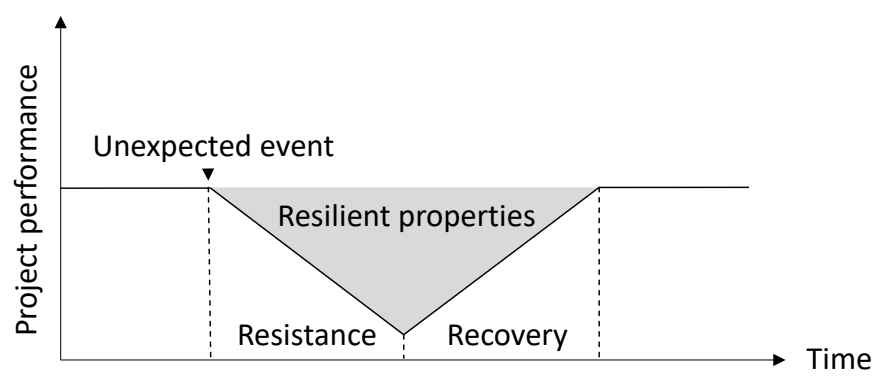

Figure 1: The performance characteristics resilient projects, adapted from Wied et al. (2020) 
Thus, this study is scoped by three concepts; 1) unexpected events, 2) project performance and 3) resilient properties mediating the relationship between the two. Adopting this as our analytical model, evaluations were reviewed, following a two-pronged approach, first proving a 'top down' overview and, second, a 'bottom up' analysis of each evaluation. Thus, evaluations were first reviewed manually and summarized in a $\sim 250$ word project abstract. Second, the detailed information in each evaluation report were coded systematically, using Atlas.ti software. Each of the three concepts are operationalized in the following.

\subsection{Unexpected events}

Following Simons (1998), the study includes 'significant' unexpected events, i.e., events that impact the ability to implement the intended plan or to realize its intended effects, creating what Gilad (2004, p. 7) calls 'dissonance' between the plan and observed reality. Following Wied et al. (2020), unexpected events can take many forms, including single-point-in-time events, permanent change, continuous fluctuation, etc. Importantly, following Williams (2017), in complex projects, unexpected events are typically the product of multiple unobserved, upstream causes, some of which are cascading and self- reinforcing. Thus, unexpected events are not necessarily traceable to a single root cause, while their consequences continue out of view, downstream in the causal chain. Finally, following Aven (2017, p. 538), unexpected events may be unexpected to some but not to others, i.e. 'unknown knowns'.

Recognizing this, we study unexpected events from the point, and at the level of abstraction, at which they are identified by evaluators. Here, an unexpected event is an observed deviation from plan, as recorded by evaluators. Thus, we define an unexpected event as the unplanned arrival of new information after project launch, with potential or realized consequences for project performance. As shown in Table III, we grouped recorded unexpected events into several classes, based on their characterization in the evaluation report. 


\subsection{Project performance}

Concepts like project 'performance', and thresholds of 'success' or 'failure' are widely discussed in the literature (de Wit, 1988; Pinto and Slevin, 1988; Jugdev and Müller, 2005; Ika, 2009; Kreiner, 2014). Notably, no consensus exists about these criteria in the broader project management literature.

Our dataset contains two indications of project performance: 1) normative assessments of projects made by evaluators and stakeholders, and 2) the resulting performance score of projects on the criteria used in the in the Norwegian performance measurement scheme. We include both of these in the study.

Turning to the first of these, the evaluations contains a wide range of normative assessments made about projects by both evaluators and stakeholders. Evaluators' assessments were given in explanation of the formal performance score of each project (see below). Stakeholders' assessments includes a broad range of opinions from parties affected by projects, interviewed for each evaluation. These vary by project and include sponsors, owners, users, environmental organizations, unions, neighbors, etc.

We analyze all normative assessments made about the projects by evaluators and stakeholders, recorded in evaluation reports. We first classify as 'normative' any statement implying an 'ought' or ‘should' (Wood, 2007, pp. 158-172). Second, following Walton (1990), we classify as 'negative' any statement implying an argument against the project, or some aspect of it, in light of an unexpected event. Conversely, we classify as 'positive' any statement implying an argument for or defense of the project, or some aspect of it, made despite, or because of, an unexpected event.

Following Komatsu (1992), we grouped assessments by shared attribute, using a two-part classification question; a) what aspect of the project was criticized/defended in light of unexpected events, and b) with reference to what performance baseline? Thus the first part identifies the 'object' criticized or defended, while the second part identifies that standard against which it is held. To achieve a mutually exclusive and collectively exhaustive classification (within the data), we followed four classification rules: 
1. All assessments in a class share one or both attributes of the classification question;

2. All final classes are non-overlapping, i.e., mutually exclusive;

3. The total classification is exhaustive, i.e., containing all normative assessments;

4. The total classification is analytically generalizable beyond the projects in the dataset.

Within these rules, the process of classification followed four steps:

1. Starting from the classification question, similar assessments were loosely grouped;

2. Groups with overlapping attributes were split as per classification rule 2 (exclusiveness);

3. Non-conforming approaches were allocated to a non-categorized residual;

4. Starting from the residual, steps 1-3 were repeated until classification rule 3 (exhaustiveness) was fulfilled.

Iterating steps 1-4 resulted in a stable grouping of tree classes of negative assessments and four classes of positive assessments (see next section). Following Cohen and Lefebvre (2005), any such bottom-up classification, i.e., not starting from pre-defined categories, is necessarily subjective, and only one of several ways to categorize the same data. Thus, alternative categorizations at both higher and lower levels of abstraction are both possible and valid. Following Gioia et al. (2013), Table V and Table VI shows the relation between assessments observed in the data and the theoretical constructs drawn from them.

The second performance indicator is evaluators' performance score on the six criteria used in the Norwegian performance measurement scheme (Samset and Volden, 2016), summarized in Table II.

\section{Table II: Standardized performance criteria about here}

Evaluators scored project performance from 1-6 on each criteria. Across criteria, a score of 4 indicates 'acceptable performance', i.e., that the project performs as planned and on a par with similar projects. Scores of 1-3 indicate less than acceptable performance, while 5-6 indicate a more than acceptable performance (The Concept Research Programme, 2015). 


\subsection{Resilient properties}

We classify, as a resilient property, any characteristic of a project which allowed project performance to resist to or recover despite, or because of, unexpected events. Following Roumboutsos et al. (2017, p. 99), we include in this adaptive properties, i.e., changes made to projects in response to unexpected events, and inherent properties, i.e., features already 'designed into' projects prior to encountering unexpected events. Thus, drawing on Meerow et al. (2016, p. 6), we include both performance 'bounce back' from negative unexpected events and 'bounce forward' from positive events. Thus, the study includes in this category any characteristic of a project allowing it to retain or regain (Henry and Ramirez-Marquez, 2016; Aven, 2017) acceptable performance after an unexpected event.

\section{Analysis and results}

This section reviews unexpected events and project performance in the 21 projects in the sample. Table III summarizes unexpected events, formal performance scores, and estimated and realized project costs.

Table III: Overview of unexpected events and formal performance scores about here.

As shown in Table III, unexpected events occurred in all projects, and most projects encountered more than one.

Table IV: Overview and examples of unexpected events about here.

Table IV gives an overview of unexpected events and illustrative examples of their types. 
Projects' scores on formal performance criteria are summarized in Table III. As shown, the impact of unexpected events led to one or more instances of underperformance in about half of the studied projects. 10 projects performed acceptably $(\geq 4)$ on all performance criteria, while 11 projects underperformed on one or more criteria (shaded). In terms of efficiency, only a single project, Project 6 , fell below acceptable performance on this criteria. On the remaining criteria, 10 projects underperformed on one or more of these. Across criteria, three projects had an average performance score of less than four (Projects 2, 11, and 21). Net present value was the most commonly underperforming score, in seven projects, followed by relevance, in four projects.

\subsection{Negative assessments of projects}

Taking a more nuanced view of the relationship between unexpected events and project performance, we turn now to negative assessments of projects from evaluators and stakeholders. We identified 93 negative assessments. Grouping these by object of criticism, three overarching meta-criticisms emerged: 1) The 'wrong project' had been chosen, 2) the 'wrong system' had been built, or 3) that 'no project' should have been undertaken. 12 projects faced more than one type of criticism, while a single project, (19) faced no negative assessments. Table $\mathrm{V}$ provides an overview of the three constructs and gives illustrative quotes from the evaluation reports.

\section{Table V: Illustrative examples of criticisms of projects about here.}

The first type of criticism targeted the project itself, arguing that it should have been implemented in a different way: Projects 1 and 5 were criticized for the order in which they were built, both projects unexpectedly encountering low demand as a result of their timing relative to the completion of adjacent rail and road projects, respectively. Project 6 was criticized for the decision to split construction into smaller sections, resulting in higher cost of the overall road. Contractual obligations forced Project 4 to abandon plans to expedite its schedule to take advantage of low prices during the 
financial crisis. The object of this class of criticisms was the project itself and the performance baseline that of 'alternative projects', in light of unexpected events.

A second type of criticism targeted the result of the project, arguing that a different system should have been built: In light of contemporary safety standards, Project 5 should have had three lanes rather than four. In project 12 , unexpectedly high traffic loads raised concerns that a broader tunnel class should have been chosen. High operating costs and unaffected relapse rates in Project 13 led to unfavorable comparisons between the new prison concept and cheaper, traditional prison concepts, and to renting capacity abroad. Project 3 was criticized for poor placement of a train station; its waterside location and distance from commuters limiting its coverage. The route choice in Project 11 was unfavorably compared to an alternative route, further from an adjacent national park, with better potential for subsequent developments, and yielding a higher net present value. The object of these criticisms was the system resulting from the project, in comparison with 'alternative systems', in light of unexpected events.

Other projects faced a more fundamental criticism, arguing, not for a different project or a different system, but that no project should have been implemented. In Project 21, newly developed navy vessels were criticized for exceeding their role, for overlaps with existing platforms, and for placing budget constraints on future defense investments. Project 14 failed to realize the expected advantages of co-locating administrative functions of a local college, as these were already largely co-located prior to the project. In addition, evaluators found no indication that the project offered better or more education, than had no project been realized. The net present value of a new opera house and ballet in Project 15 was unfavorably compared to continuing performances in the existing theatre. In Project 1 , evaluators raised the question of whether, given substantial cost cutting and reduced technical standards, it would still be worth implementing the project. In light of heavy traffic growth in Project 9, evaluators questioned whether the road expansion would, counter-productively, increase congestion further in the long run. Thus, these criticisms unfavorably compared both the project and its result, but 
against a performance baseline of 'no project' as a potentially superior alternative in light of unexpected events.

\subsection{Positive assessments of projects}

Normative assessments also included arguments in defense of projects, i.e., arguments that projects had either retained or regained acceptable performance despite, or because of, unexpected events. We identified 112 positive assessments made by evaluators and stakeholders.

Grouping these by baseline of acceptable performance, four overarching themes emerged, i.e., 1) that, while worse than expected, the project was still 'superior', 2) that alternatives would have fared no better, 3) that the project 'compensated', i.e., performed worse in some ways, but better in others, and 3) that the project switched to a better alternative. Table VI provides an overview of the four constructs and gives illustrative quotes from the evaluation reports.

Table VI: Illustrative examples of defenses of projects about here.

As shown in Table VI, one defense held that the chosen project remained superior to competing alternatives, despite negative unexpected events. In these cases, resilience to unexpected events was achieved through sufficient initial superiority over competing alternatives or even 'monopoly', i.e., that no alternatives were available. As shown, Project 4 and 12 were defended with reference to an undesirable status quo, while the apparent alternative to Project 15 was considered infeasible. Thus, projects retained superiority over competing alternatives, in the eyes of defending stakeholders, despite unexpected events.

A second defense held that, while the project encountered unexpected events, competing alternatives would have been similarly affected, i.e., would have 'fared no better'. Projects 13 and 21 encountered market conditions that would have similarly affected competing alternatives, and the queueing problem encountered by Project 16 would not have been addressed by opting for the known 14 
alternative. In these cases, projects were defended from unexpected events by a 'shared fate' with competing alternatives, thus retaining equivalent performance to these.

A third defense held that, while the project underperformed in some ways, it overperformed in others. Thus, on balance, the project regained superiority over competing alternatives. As shown, in e.g. Project 19 and 4, these projects regained superiority over competing alternatives by exposure to compensatory positive events.

A final type of defense held that, while competing alternatives unexpectedly proved superior, these were successfully adopted by the project. Project 18 and 21, as shown, regained superiority in the eyes of defending stakeholders by converting to a superior alternative, in response to unexpected events.

\section{Findings and implications}

Turning to the first research question of the relationship between unexpected events and project performance; unexpected events occurred in all projects, while causing underperformance in about half of the projects in the sample. As shown in Table IV, changing requirements beyond the control of the project, technical problems, planning error, and demand changes were the most common types events encountered. Notably, as shown in Table III, removing planning error as a factor, does not change the finding that all projects encountered significant unexpected events.

Further, negative assessments of projects suggest that unexpected events do not necessarily cause underperformance, formal success criteria. As shown in Table VII, criticisms and defenses were made of formal performers and underperformers.

Table VII: Criticisms and defenses of performing and underperforming projects (number of projects) about here. 
As shown, in the eyes of stakeholders, projects resisted, recovered or underperformed - not necessarily relative to budget, schedule, plan, prior expectations, or in comparison to similar projects but relative to competing alternatives foregone by their implementation. This suggests a performance baseline - unique to each project - of whether its stakeholders, in hindsight, continue to prefer it to a counter factual option foregone - whether known or imagined.

This view of project performance has important implications for understanding the impact of unexpected events. Unexpected events cause failure in the eyes of its stakeholders when it is no longer superior to one or more competing alternatives. As shown in Table V, we identified three such alternatives, shown in Fig. 2 as four mutually exclusive pathways, one chosen and three foregone.

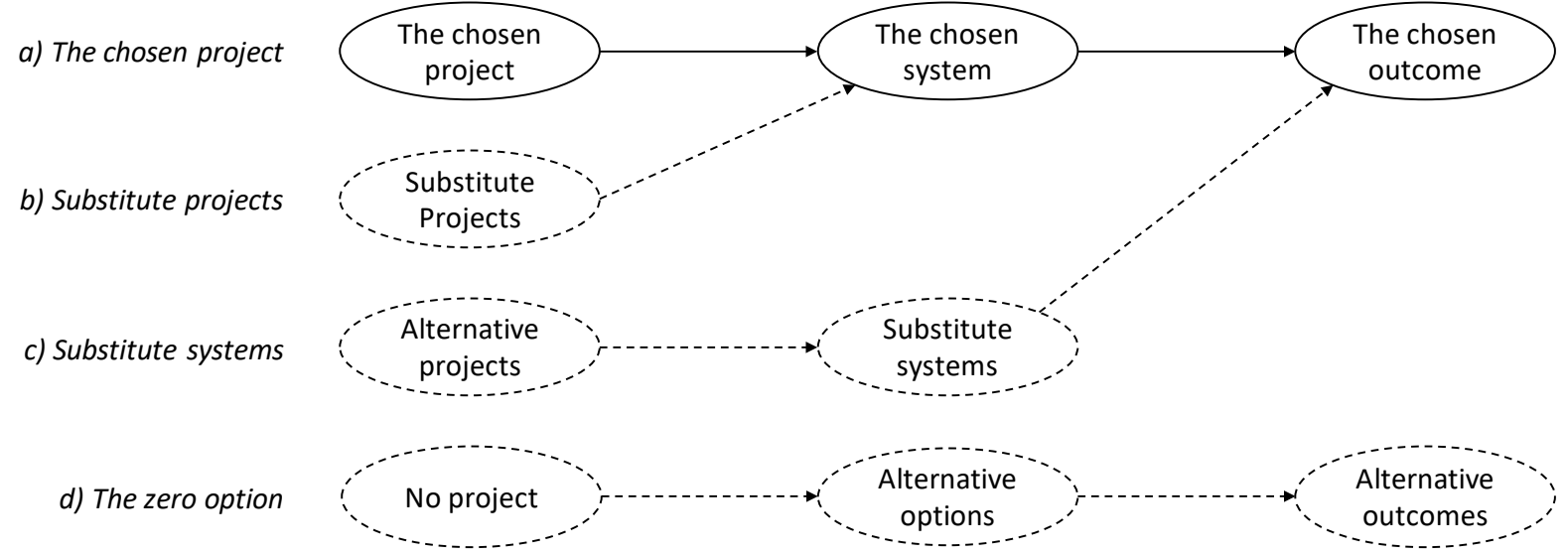

Figure 2: Three competing alternatives to a chosen project

Fig. 2a shows a chosen project aimed at building a chosen system producing a chosen outcome. Fig. 2 also shows three principal competing alternatives, including b) the set of known substitute projects, i.e., different ways of creating the same system, $c$ ) the set of alternative projects aimed at building substitute systems, also capable of achieving the chosen outcome, and d) the zero option, that is, implementing 'no project', thus retaining alternative options for achieving alternative outcomes.

Corresponding to these pathways, the stakeholder landscape surrounding any project can be segmented into four principal positions Fig. 3. 


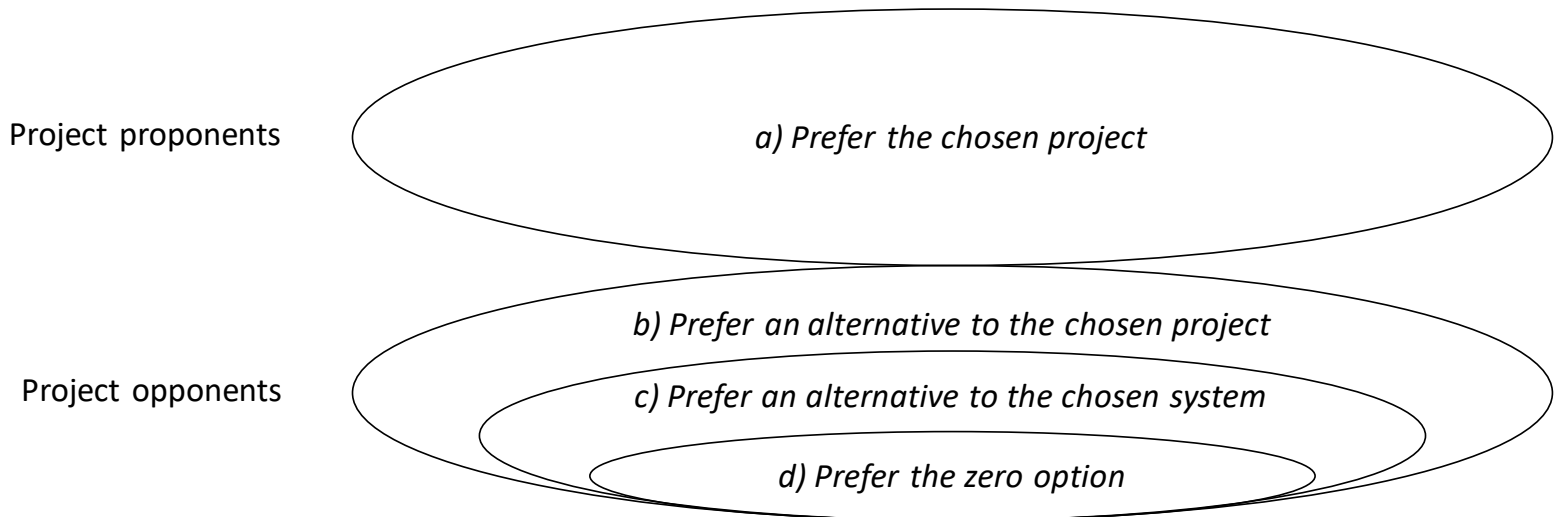

Figure 3: Four principal positions in the stakeholder landscape

Fig. 3 distinguishes between project proponents, preferring the chosen project over competing alternatives, and project opponents, preferring one or more competing alternatives.

\subsection{When unexpected events matter}

In this view, unexpected events matter when they affect stakeholders' preference for the chosen project relative to one or more competing alternatives, potentially causing stakeholders to 'migrate' from the proponent group and into the opponent group. Logically, this can occur in two ways: 1) If the chosen project underperforms relative to competing alternatives, or if 2), one or more competing alternatives overperform relative to the chosen project.

For example, unaffected relapse rates and higher operational costs reduced the attractiveness of Project 13 relative to traditional prison concepts and to renting capacity abroad. Conversely, in Project 5, a competing alternative overperformed; the unexpected advantages of an alternative route decreased the attractiveness of the chosen route. Fig. 4 shows these two cases, illustrating the pivotal points at which stakeholder preferences switch from the chosen project to competing alternatives.

The chosen project underperforms

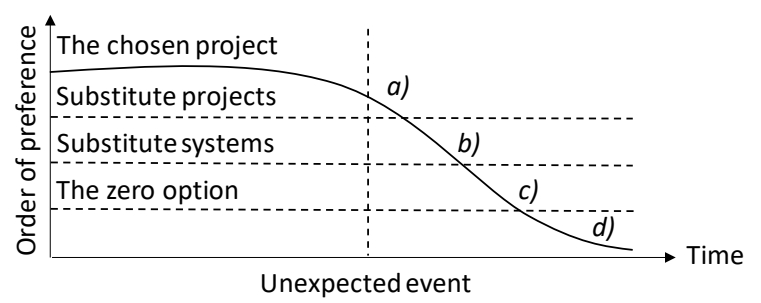

17
Competing alternatives overperform

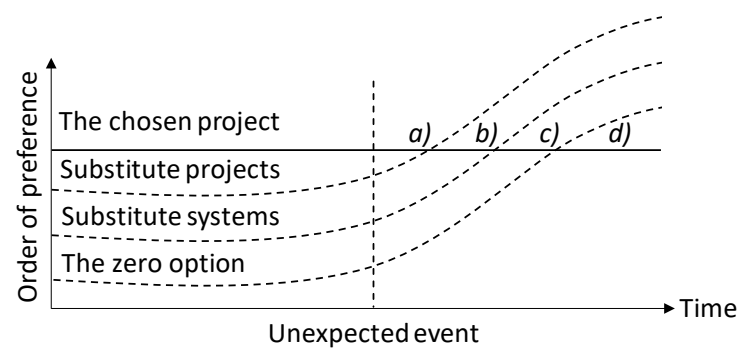


Figure 4: Two causes of project underperformance (the order of competing alternatives is arbitrary)

As shown, unexpected events lead to underperformance when they cause project proponents to change their preference for the project a), over one or more alternatives foregone; b), c), or $d$ ). Conversely, positive unexpected events can cause opponents to 'migrate' in the opposite direction to join or (rejoin) the proponent group, as new information emerge.

Thus, unexpected events 'matter' only if they affect the performance of the chosen project relative to competing alternatives, while absolute performance changes are irrelevant. This implies the existence of two special classes of unexpected events: 'Negative boons', i.e., events reducing the absolute performance of a project, but, increasing its relative performance to foregone alternatives. The corollary, 'positive banes', improve a project's absolute performance, and, at the same time, reduce its relative performance to (even) more attractive alternatives. In both cases, the chosen project remain the preferred choice in the eyes of stakeholders.

\subsection{Resilience to unexpected events}

Turning now to the second the research question regarding the shared properties allowing some projects to succeed despite, or even because of, unexpected events.

Table VI distinguishes four defenses of projects, i.e., arguments that projects either retained or regained acceptable performance after an unexpected event, in the eyes of project proponents. Correspondingly, the four defenses are illustrated in Fig. 5, both for the case of underperformance of the chosen project and overperformance of competing alternatives. 


\section{- Superiority-}

a) The project underperforms, but remains superior

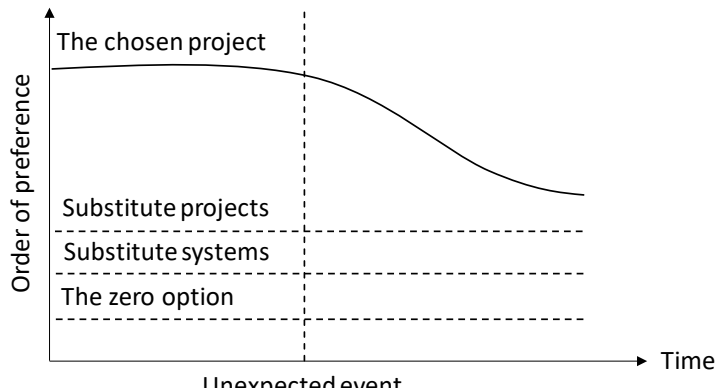

\section{- Equivalence-}

d) The project underperforms, but so do alternatives

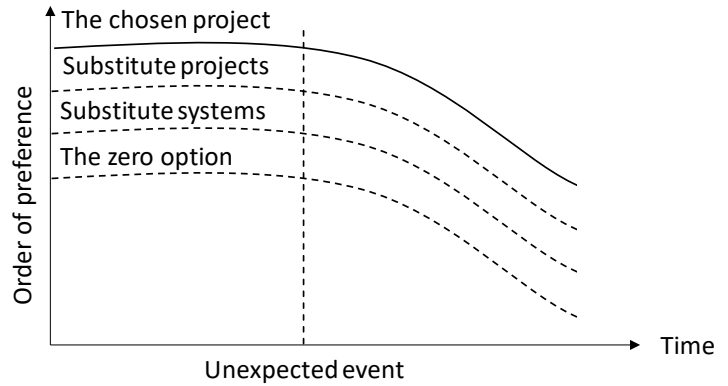

b) Alternatives overperform, but remain inferior

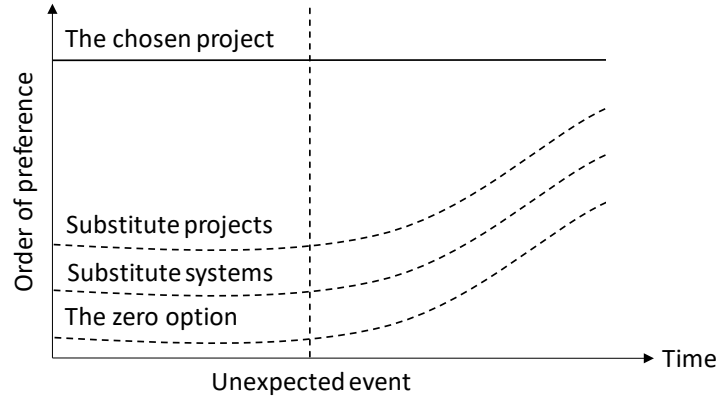

\section{- Compensation -}

c) The project underperforms, but compensates

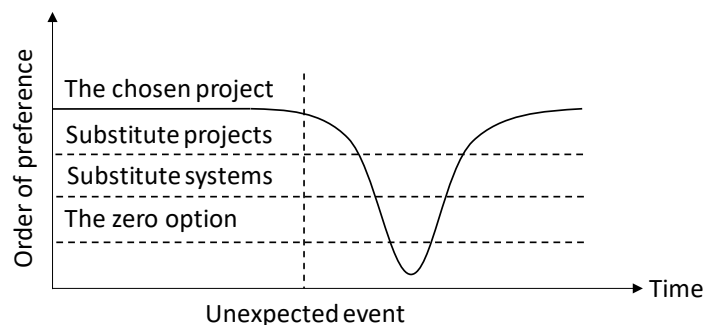

f) Alternatives overperform, but so does the project

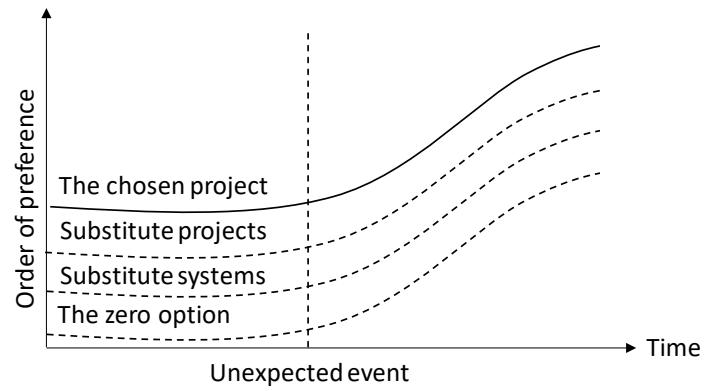

\section{- Convertibility -}

e) The project underperform, but an alternative is adopted

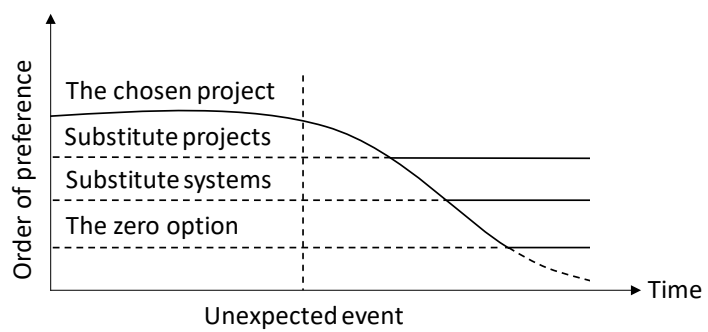

d) Alternatives overperform, but compensates

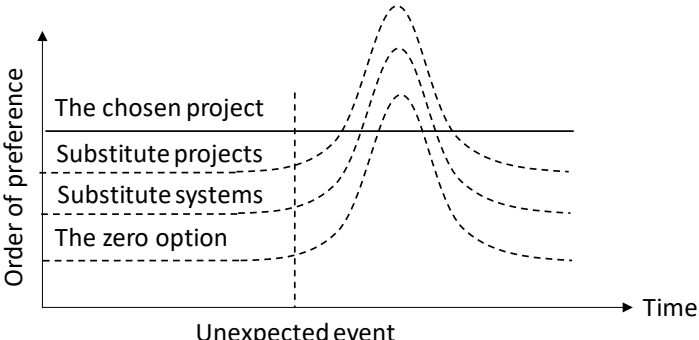

Unexpected event f) Alternatives overperform, but are adopted by the project

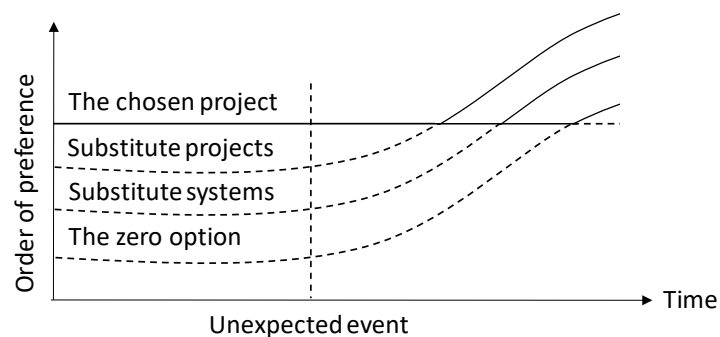

Figure 5: Functions of project resilience 
As shown, superiority and equivalence allow projects to retain superiority over competing alternatives. Conversely, compensation and convertibility allows projects regain superiority.

Building on this, Table VIII describes the key characteristics of resilient projects. It also describes the characteristics of their corollary; brittle projects. Here, we borrow the adjective 'brittle' from Kalra et al. (2014, p. 4), to denote projects able to succeed only given a narrow set of assumptions.

\section{Table VIII: Characteristics of resilient and brittle projects about here.}

From a planning perspective, the framework provides rudimentary design criteria for reconceptualizing, rescheduling or relocating projects for greater resilience. From a project selection perspective, the framework provides arguments for undertaking resilient projects, while brittle properties are 'red flags', indicating the dependence of a project on its planners 'being right' about the future. In this sense, the framework provides arguments against undertaking brittle projects, even if seemingly well-planned, and independently reviewed and to be implemented by experienced people.

\section{Discussion}

Moving beyond existing resilience research into the characteristics of projects organizations, this study focused on the properties of the endeavors they undertake. We adopted the premises of resilience theory, that while events are inevitable, some projects - inadvertently or by design - have properties allowing them to resist or recover from unexpected events, while others do not. Unlike the traditional emphasis in project management on projects that are 'right and successful' (Flyvbjerg, 2014, p. 11) or 'wrong and failed' (Locatelli, 2018), we turned our attention to properties of projects that are 'wrong, but not failed'.

First, our findings lends credence to the premise of the resilience paradigm, that in complex projects, unexpected events occur regardless of sophisticated up-front planning and independent plan reviews. 
Despite the quality assurance scheme, all projects in the sample encountered significant unexpected events. Notably, eliminating planning error as a factor does not change this finding. Unexpected events led to one or more instances of underperformance in about half of all projects, measured on formal performance criteria. In line with Geraldi (2010), Lenfle and Loch (2010) and Crosby (2014), this suggests that the ability to succeed despite, or because of, unexpected events, may be a more fruitful avenue of improvement than further efforts to anticipate, prevent, and mitigate unexpected events up-front.

Second, departing from formal performance criteria, our findings shed light on the relationship between unexpected events and project performance. Our findings suggest that projects do not necessarily 'succeed' or 'fail' relative to formal performance criteria. Adherence to budget, schedule, plan, prior expectations, or the results of similar projects is neither necessary nor sufficient for acceptable project performance in the eyes of stakeholders. Here, our findings line up with Hällgren and Wilson (2008, p. 830), noting a similar phenomenon "In some cases, [unexpected] events do not seem to matter and are thus tolerated."

We depart from the presumption that unexpected events (necessarily) matter when they impact predetermined formal performance criteria, e.g. as the Norwegian performance measurement scheme and in the wider project management literature (de Wit, 1988; Pinto and Slevin, 1988; Jugdev and Müller, 2005; Ika, 2009; Kreiner, 2014). Our findings likewise depart from the 'minimax regret' criteria proposed by Savage (1951); no defensive argument in our sample held the ground of minimized worst-case regret, i.e., that while a competing alternative proved superior, the project was the 'least inferior' or 'second best' option.

Our findings suggest an alternative and perhaps more fundamental performance baseline. Unexpected events matter when they affect stakeholders' preference for a chosen project relative to known or imagined competing alternatives, foregone by its implementation. In this view, the life cycle of a project is an ongoing deliberation between project proponents and opponents, through which unexpected events strengthen or weaken the preference for the chosen project, relative to its 
competing alternatives. Here, our findings align with Simon (1997, p. 111), suggesting that 'success' essentially means turning "existing situations into preferred ones." In doing so, we argue for an essentially a 'subjective opportunity cost' view of project performance.

Identifying four of properties of project able to retain or regain superiority over competing alternatives, we outlined a set of rudimentary design principles for project planning and selection. Departing from traditional efforts to 'de risk plans' and 'de-bias planners' (Cantarelli et al., 2010; Samset, 2010; Merrow, 2011; Samset and Volden, 2016), these prescriptions focus exclusively on the properties of projects themselves, not on presumed foreknowledge of future events. Thus, operationalizing the two principles of resilience theory (Holling, 1973, p. 21), we have argued for an ethos of Socratic humility about the future as a basis for developing general preparedness in the face of an unknown future.

\section{Conclusion}

This paper identified two approaches to the problem of unexpected events in complex engineering projects. Through the eyes of the anticipatory paradigm, such events are symptomatic of poor planning, bias, and inaccurate forecasts. Through the eyes of the resilience paradigm, unexpected events are inevitable, although some projects - inadvertently or by design - have properties allowing them to resist or recover from unexpected events. Adopting the latter paradigm, we investigated 1) how unexpected events impact project performance, and 2) sought to identify the properties allowing some projects to succeed, despite or even because of unexpected events.

We investigated unexpected events and performance in 21 engineering projects in Norway, reviewing ex post evaluations 3-12 years after project completion. Despite independent quality review of all project plans, we identified significant unexpected events in all projects. Notably, eliminating planning error as a factor did not change this finding. Thus, our study lends credence to the view that unexpected events occur despite sophisticated up-front planning procedures. Further, these unexpected 
events led to one or more instances of underperformance, on formal performance criteria, in about half of all projects in the sample.

Analyzing evaluators' and stakeholders' criticisms and defenses of projects we found that unexpected events matter when they affect stakeholders' preference for a project relative to one or more known or imagined competing alternatives. Thus, our findings suggests that, unexpected events cause underperformance - not necessarily relative to budget, schedule, plan, prior expectations, or compared to similar projects - but relative to competing alternatives, known or imagined, foregone by their implementation.

Finally, we identified four properties of projects able to succeed despite, or because of, unexpected events. Outlining a prescriptive framework for project planning and selection, we proposed superiority, equivalence, compensation, and convertibility as alternative planning and selection criteria. Superior projects have sufficient superiority over competing alternatives to remain superior, despite unexpected events. Equivalent projects face similar challenges, activities, and conditions, thus, 'faring no better' than competing alternatives. Third, compensatory projects can compensate for underperformance in one domain by overperforming in another, thus regaining superiority over competing alternatives. Finally, convertible projects contain several competing alternatives within their scope. Thus, operationalizing the two principles of resilience theory, we have argued for an ethos of Socratic humility about the future as a basis for developing general preparedness.

Our findings calls for further research into the properties of complex engineering projects enjoying continued support from their stakeholders in a future quite different from the one imagined at its outset, i.e., into projects that are 'wrong, but not failed.' Further research in this vein will show if our prescriptions are exhaustive and delve into the practical requirements and impacts of resilient project planning and selection. In addition, following Aven (2019), there is room for further exploration of the synergies between resilience and anticipatory planning, as these are clearly not mutually exclusive. Fundamentally, their combined prescription would be to make the best plan possible, but to act as if that same plan has a crucial flaw to be discovered only after project launch. 


\section{References}

Apostolakis, G. E. (2004) 'How useful is quantitative risk assessment?', Risk Analysis, 24(3), pp. 515520. doi: $10.1111 / \mathrm{j} .0272-4332.2004 .00455 . x$.

Aven, T. (2017) 'How some types of risk assessments can support resilience analysis and management', Reliability Engineering and System Safety. Elsevier Ltd, 167(August 2016), pp. 536543. doi: 10.1016/j.ress.2017.07.005.

Aven, T. (2019) 'The Call for a Shift from Risk to Resilience: What Does it Mean?', Risk Analysis, 39(6), pp. 1196-1203. doi: 10.1111/risa.13247.

Beedle, M. et al. (2001) 'Manifesto for Agile Software Development', pp. 2-3. Available at: https://www.researchgate.net/file.PostFileLoader.html?id=57d055b593553b11467ddd59\&assetKey= AS\%3A403742915612673\%401473271220194.

Bertalanffy, L. Von (1969) General System Theory: Foundations, Development, Applications. Revised ed. George Braziller Inc.

Black, F. and Scholes, M. (1973) 'The Pricing of Options and Corporate Liabilities', The Journal of Political Economy, 81(3), pp. 637-654.

Bogdanov, A. A. (1917) Bogdanov's Tektology: Book 1. 1996 aditi. Edited by P. Dudley. Hull, UK: Centre for Systems Studies Press.

de Bruijne, M. and van Eeten, M. (2007) 'Systems that should have failed: Critical infrastructure protection in an institutionally fragmented environment', Journal of Contingencies and Crisis Management, 15(1), pp. 18-29. doi: 10.1111/j.1468-5973.2007.00501.x.

Cantarelli, C. C. et al. (2010) 'Cost overruns in large-scale transportation infrastructure projects: Explanations and their theoretical embeddedness', European Journal of Transport and Infrastructure Research, 10(1), pp. 5-18.

Cohen, H. and Lefebvre, C. (2005) Handbook of Categorization in Cognitive Science. First edit, Handbook of Categorization in Cognitive Science. First edit. Elsevier. doi: 10.1016/B978-0-08-0446127.X5053-7.

Crosby, P. (2012) 'Building Resilience in Large High-Technology Projects : Front End Conditioning for Success', Int. J. Information Technology and Project Management, 3(4).

Crosby, P. (2014) 'Success in large high-technology projects: What really works?', Proceedings of SPIE - The International Society for Optical Engineering, 9150, pp. 1-14. doi: 10.1117/12.2057972.

Daneshgari, P. and Wilson, M. (2006) 'The profitability of agile construction', Building Profits, pp. 816.

Dvir, D. and Lechler, T. (2004) 'Plans are nothing, changing plans is everything: The impact of changes on project success', Research Policy, 33(1), pp. 1-15. doi: 10.1016/j.respol.2003.04.001.

ECPD (1947) Canons of ethics for engineers. New York: Engineers' Council for Professional Development.

Engwall, M. (2003) 'No project is an island: Linking projects to history and context', Research Policy, 32(5), pp. 789-808. doi: 10.1016/S0048-7333(02)00088-4.

Flyvbjerg, B. (2014) 'What You Should Know About Megaprojects and Why: An Overview', Project 
Management Journal, 45(2), pp. 6-19. doi: 10.1002/pmj.

Flyvbjerg, B., Bruzelius, N. and Rothengatter, W. (2003) Megaprojects and risk: An anatomy of ambition. Cambridge University Press.

Geraldi, J. (2010) 'The Titanic sunk, so what? Project manager response to unexpected events', International Journal of Project Management, 28, pp. 547-558. doi: 10.1108/sd.2011.05627aad.002.

Gilad, B. (2004) Early Warning: Using Competitive Intellingence to Anticipate Market Shifts, Control Risk, and Create Powerful Strategies. New York, USA: American Management Association.

Gioia, D. A., Corley, K. G. and Hamilton, A. L. (2013) 'Seeking Qualitative Rigor in Inductive Research: Notes on the Gioia Methodology', Organizational Research Methods, 16(1), pp. 15-31. doi: $10.1177 / 1094428112452151$.

Hällgren, M. and Wilson, T. L. (2008) 'The nature and management of crises in construction projects: Projects-as-practice observations', International Journal of Project Management, 26(8), pp. 830-838. doi: 10.1016/j.ijproman.2007.10.005.

Henry, D. and Ramirez-Marquez, J. E. (2016) 'On the Impacts of Power Outages during Hurricane Sandy-A Resilience-Based Analysis', Systems Engineering, 19(1), pp. 59-75. doi: 10.1002/sys.21338.

Holling, C. S. (1973) 'Resilience and stability of ecological systems', Annu.Rev.Ecol.Syst., 4, pp. 1-23. doi: 10.1146/annurev.es.04.110173.000245.

Ika, L. A. (2009) 'Project Success as a Topic in Project Management Journals', Project Management Journal, 40(4), pp. 6-19. doi: DOI: 10.1002/pmj.20137.

Jugdev, K. and Müller, R. (2005) 'A Retrospective Look At Our Evolving For Project Success', Project Management Journal, 36, pp. 19-32. doi: 10.1109/EMR.2006.261387.

Kalra, N. et al. (2014) 'Agreeing on Robust Decisions New Processes for Decision Making Under Deep Uncertainty', World Bank Policy Research Working Paper, No. 6906(June). doi: doi:10.1596/18139450-6906.

Kaplan, B. S. and Garrick, J. (1981) 'On the quantitative definition of risk', Risk Analysis, 1(1), pp. 1127. doi: 10.1111/j.1539-6924.1981.tb01350.x.

Karlsen, J. T. and Berg, M. E. (2020) 'A study of the influence of project managers' signature strengths on project team resilience', Team Performance Management, 26(3-4), pp. 247-262. doi:

10.1108/TPM-12-2018-0081.

Komatsu, L. K. (1992) 'Recent views of conceptual structure', Psychological Bulletin, 112(3), pp. 500526. doi: 10.1037//0033-2909.112.3.500.

KPMG (2017) 'Foresight: A global infrastructure perspective - Ten emerging trends in 2017', Special ed(January).

Kreiner, K. (2014) 'Restoring project success as phenomenon', in Lundin, R. A. and Hällgren, M. (eds) Advancing Research on Projects and Temporary Organizations. Copenhagen Business School Press., pp. 19-38.

Kutsch, E., Browning, T. R. and Hall, M. (2014) 'Bridging the Risk Gap: The Failure of Risk Management in Information Systems Projects', Research Technology Management, 57(2), pp. 26-32. doi: $10.5437 / 08956308 \times 5702133$.

Kutsch, E., Hall, M. and Turner, N. (2016) Project Resilience: The Art of Noticing, Interpreting, 
Preparing, Containing and Recovering. New York, USA: Routledge.

Kvale, S. (1996) Interviews : an introduction to qualitative research interviewing. Sage Publications. doi: 10.1016/S1098-2140(99)80208-2.

Lempert, R. J., Popper, S. W. and Bankes, S. C. (2003) Shaping the Next One Hundred Years: New Methods for Quantitative, Long-Term Policy Analysis, Technological Forecasting and Social Change. RAND. doi: 10.1016/j.techfore.2003.09.006.

Lenfle, S. (2014) 'Toward a genealogy of project management: Sidewinder and the management of exploratory projects', International Journal of Project Management. Elsevier Ltd and IPMA, 32(6), pp. 921-931. doi: 10.1016/j.ijproman.2013.10.017.

Lenfle, S. and Loch, C. (2010) 'Lost Roots: How Project Management Came to Emphasize Control over Flexibility and Novelty', California Management Review, 53(1), pp. 32-55. doi:

10.1525/cmr.2010.53.1.32.

Locatelli, G. (2018) 'Why are Megaprojects, Including Nuclear Power Plants, Delivered Overbudget and Late? Reasons and Remedies', Center for Advanced Nuclear Energy Systems (CANES), Massachusetts Institute of Technology, 2018, pp. 1-28.

Loch, C. H., DeMeyer, A. and Pich, M. T. (2006) Managing the Unknown: A New Approach to Managing High Uncertainty and Risk in Projects. John Wiley \& Sons, Inc.

McAdam, D. (2011) 'Social movements and the growth in opposition to global projects', in Scott, W. R., Levitt, R. E., and Orr, R. J. (eds) Global Projects: Institutional and Political Challenges. Cambridge: Cambridge University Press, pp. 86-110. doi: 10.1017/СBO9780511792533.005.

Meerow, S. and Stults, M. (2016) 'Comparing conceptualizations of urban climate resilience in theory and practice', Sustainability (Switzerland), 8(7), pp. 1-16. doi: 10.3390/su8070701.

Merrow, E. W. (2011) Industrial Megaprojects: Concepts, Strategies, and Practices for Success. Wiley.

Merrow, E. W. and Nandurdikar, N. (2018) Leading Complex Projects: A Data-Driven Approach to Mastering the Human Side of Project Management. John Wiley \& Sons Inc.

de Meyer, A., Loch, C. H. and Pich, M. T. (2002) 'Managing Project Uncertainty: From Variation to Chaos', MIT Sloan Management Review, 43(Winter), pp. 60-67. doi: 10.1109/EMR.2002.1032403.

Miller, R. and Lessard, D. (2001) The strategic management of large engineering projects. 1st edn. The MIT Press.

Montanari, L. and Querzoni, L. (2014) 'Critical Infrastructure Protection : Threats, Attacks and Countermeasures', Tenace, (March), pp. 1-164.

Morra, L. G. and Thumm, U. R. W. (1997) Evaluation Results 1995, The International Bank for Reconstruction and Development. Washington DC.

Morris, P. W. G. and Hough, G. H. (1991) The Anatomy of Major Projects: A Study of the Reality of Project Management. Chichester: John Wiley \& Sons, Inc.

Naderpajouh, N. et al. (2020) 'Resilience and Projects: An Interdisciplinary Crossroad', Project Leadership and Society. Elsevier Ltd, 1(1). doi: 10.1016/j.plas.2020.100001.

Nicholas, J. M. (2004) Project Management for Business and Engineering: Principles and Practice. A Butterwo. Elsevier Butterworth-Heinemann, UK.

Olsson, N. O. E. (2008) 'External and internal flexibility - aligning projects with the business strategy 26 
and executing projects efficiently', International Journal of Project Organisation and Management, 1(1), pp. 47-64. doi: 10.1504/IJPOM.2008.020028.

Olsson, N. O. E. (2016) 'Reduction lists as tool for cost control in public building projects', Journal of Facilities Management, 14(1), pp. 84-100. doi: 10.1108/JFM-06-2015-0022.

Owen, R. et al. (2006) 'Is agile project management applicable to construction?', in Salford Centre for Research and Innovation. Proceedings IGLC-14, July 2006, Santiago, Chile, pp. 51-66. doi: 10.1111/j.1467-9302.2008.00617.x.

Pich, M. T., Loch, C. H. and de Meyer, A. (2002) 'On Uncertainty, Ambiguity, and Complexity in Project Management', Management Science, 48(8), pp. 1008-1023. doi: 10.1287/mnsc.48.8.1008.163.

Pinto, J. K. and Slevin, D. P. (1988) 'Project Success : Definitions and Measurement Techniques', Project Management Journal, 19(1), pp. 67-72. doi: 10.1016/j.emj.2004.09.011.

Roberts, K. H. (1984) 'New challenges in organizational research: high reliability organizations', Organization \& Environment, 2(2). doi: https://doi.org/10.1177/108602668900300202.

Rolstadås, A. et al. (2011) Risk Navigation Strategies for Major Capital Projects: Beyond the Myth of Predictability, Springer Series in Reliability Engineering. London: Springer. doi: 10.1007/978-0-85729594-1.

Rose, A. (2017) Defining and Measuring Economic Resilience from a Societal, Environmental and Security Perspective. Springer. doi: 10.1007/978-981-10-1533-5.

Roumboutsos, A., Voordjik, H. and Pantelias, A. (2017) Funding and financing transport infrastructure: Business Models to Enhance and Enable Financing of Infrastructure in Transport. Longon \& New York: Routledge.

Samset, K. (2003) Project evaluation. Making investments succeed. Trondheim, Norway: Fagbokforlaget.

Samset, K. (2010) Early Project Appraisal. New York: Palgrave Maximillian.

Samset, K. F. and Volden, G. H. (2014) 'The impact of external quality assurance up front to improve governance of major public investment projects', in Paper presented at Project Management Institute Research and Education Conference, Phoenix, AZ. Newtown Square, PA: Project Management Institute.

Samset, K. and Volden, G. H. (2016) 'Front-end definition of projects: Ten paradoxes and some reflections regarding project management and project governance', International Journal of Project Management. Elsevier Ltd and Association for Project Management and the International Project Management Association, 34(2), pp. 297-313. doi: 10.1016/j.ijproman.2015.01.014.

Savage, L. J. (1951) 'The theory of statistical decision', Journal of the American Statistical Association, 46, pp. 55-67.

Schwaber, K. and Beedle, M. (2002) Agile software development with Scrum. Prentice Hall.

Shenhar, A. J. and Dvir, D. (1996) 'Toward a typological theory of project management', Research Policy, 25(4), pp. 607-632. doi: 10.1016/0048-7333(95)00877-2.

Shenhar, A. J. and Dvir, D. (2007) Reinventing project management: The diamond approach to successful growth and innovation. Boston: Harvard Business School Press.

Simon, H. A. (1997) The sciences of the artificial, (third edition), Computers \& Mathematics with 
Applications. doi: 10.1016/S0898-1221(97)82941-0.

Simons, R. L. (1998) 'A Note on Identifying Strategic Risk'. Harvard Business School, note \# 9-199-031, 1998.

Söderlund, J. (2004) 'On the broadening scope of the research on projects: A review and a model for analysis', International Journal of Project Management, 22(8), pp. 655-667. doi:

10.1016/j.ijproman.2004.05.011.

Sommer, S. C. and Loch, C. H. (2004) 'Selectionism and Learning in Projects with Complexity and Unforeseeable Uncertainty', Management Science, 50(10), pp. 1334-1347. doi:

$10.1287 /$ mnsc. 1040.0274 .

The Concept Research Programme (2015) Etterevaluering av statlige investeringsprosjekter i regi av Concept-programmet. Retningslinjer for evaluator.

Turner, Michelle; Scott-Young, Christina; Holdsworth, S. (2019) 'Developing the resilient project professional: examining the student experience', International Journal of Managing Projects in Business, 12(3), pp. 716-729. doi: 10.1108/IJMPB-01-2018-0001.

Volden, G. H. and Samset, K. (2017) A Close-up on Public Investment Cases. Lessons from Ex-post Evaluations of 20 Major Norwegian Projects. Trondheim, Norway.

Walton, D. (1990) Practical Reasoning: Goal-Driven, Knowledge-Based, Action-Guiding Argumentation. Savage, Maryland, Rowman and Littlefield.

de Weck, O., Magee, C. L. and Roos, D. (2011) Engineering Systems: Meeting Human Needs in a Complex Technological World. Cambridge, Massachusetts: The MIT Press.

Weick, K. E. and Sutcliffe, K. M. (2007) Managing the unexpected: Sustained Performance in a Complex World. Second edi. Wiley \& Sons Inc.

Wied, M. et al. (2020) 'Managing exploratory projects: A repertoire of approaches and their shared underpinnings', International Journal of Project Management, 38(2), pp. 75-84.

Wied, M., Oehmen, J. and Welo, T. (2020) 'Conceptualising resilience in engineering systems: An analysis of the literature', Systems Engineering, 23(1), pp. 3-13. doi:

https://doi.org/10.1002/sys.21491.

Williams, T. (2005) 'Assessing and moving on from the dominant project management discourse in the light of project overruns', IEEE Transactions on Engineering Management, 52(4), pp. 497-508. doi: 10.1109/TEM.2005.856572.

Williams, T. (2017) 'The Nature Of Risk In Complex Projects', Project Management Journal, 48(4), pp. $55-66$.

de Wit, A. (1988) 'Measurement of project success', International Journal of Project Management, 6(3), pp. 164-170. doi: 10.1016/0263-7863(88)90043-9.

Wood, N. (2007) Perspectives on Argument. 5th ed. New York: Pearson.

Yin, R. K. (2014) Case Study Research Design and Methods. 5th editio. Thousand Oaks, CA: Sage. doi: 10.3138/cjpe.30.1.108. 